\title{
OS HOSPITAIS: LUGAR DE DOENTES E DE OUTROS PERSONAGENS MENOS REFERENCIADOS
}

\author{
THE HOSPITALS: PLACE OF SICK PEOPLE AND OTHER PERSONAES LESS \\ REFERENCED \\ LOS HOSPITALES: LUGAR DE ENFERMOS Y DE OTROS PERSONAGES MENOS \\ REFERENCIADOS
}

\section{Cleuza Panisset Ornellas}

\begin{abstract}
RESUMO: Os hospitais foram, desde sua origem, um lugar de recolhimento e abrigo de doentes. A igreja. na ldade Média, fundou hospitais nos mosteiros, onde os doentes recebiam cuidados e assistência, antes religiosa que terapêutica. Ao final da Idade Média, os hospitais tornaram-se um lugar de exclusão, para onde foram encaminhados os loucos, os leprosos e os mendigos, juntamente com os doentes. Com o surgimento da clínica, o hospital tornou-se o espaço privilegiado onde os doentes puderam ser observados e a arte de cuidar consolidou-se. A apreensão das práticas de cuidar pelo modo de produção capitalista muda o caráter acolhedor do hospital, que passa a ser um instrumento de trabalho. espaço produtivo não só de tratamentos mas, principalmente, de valores.
\end{abstract}

UNITERMOS: Hospitais - Modo de produção - Prática médica - Arte de cuidar .

ABSTRACT: The hospitals were, since its source, a place of retirement and shelter of sick people.The Church, in Middle Age, founded hospitals in their monasteries, where sich people took care anda assistance, more religious than therapeutic. In the final of Middle Age the hospital became an exclusion's place for the crazy people, the leprous people, the bec people and the sich people were guided to. With de arisemens hospital became privilegious space where sick people could be observed and the art of care was consolidate. The apprehension of care practices by the capitalism way of production changed the wel coming character of the hospital that would be an instrument of work, productive space not only of treatment beut, foremost, of values.

KEYWORDS: Hospitals - Medical practice - Way of production.

RESUMEN: LOs hospitales fueron desde su origem lugares de hospitalidad y abrigo de los enfermos.La Iglesia, en la Edad Media, ha fundadao hospitales en los mosteros, donde los enfermos recibiam cuidados y asistencia, mas religiosa que terapeutica.Ao final de la Edad Medialos hospitales volvien a ser un lugar de exclusión para donde se encaminavan los locos, los mendigos, los leprosos, juntamente com los enfermos.Com el surgimiento de la clínica, ele hospital viene a ser el lugar privilegiado onde los enfermos podiam ser observados e el arte de cuidar se ha consolidado. La apreensión de las practicas de cuidar y asistir por el modo de produción capitalista muda el carater hospitalero del hospital que pasa a ser un instrumento de trabaljo, espacio produtivo, non solamiente de tratamiento y cuidado, mas, principalmiente de valores.

UNITÉRMINOS: Hospitales - Modo de producción - Práctica médica - Arte de cuidar.

${ }^{1}$ Dra. em Saúde Coletiva da UNICAMP. Prof ${ }^{\mathrm{a}}$ Visitante na Universidade de Pelotas.

R. Bras. Enferm. Brasilia, v. 51, n. 2, p. 253-262, abr.jun., 1998 
Este trabalho analisa os hospitais, tomando por referência a característica de serem historicamente o lugar preferencial do exercício da medicina e da enfermagem e de acolhimento dos doentes. A análise compreende o processo pelo qual estes estabelecimentos tornaram-se o espaço onde a prática médica definiu-se como instituição hegemônica do cuidado e tratamento dos doentes até a sua conformação contemporânea de organização de produção e consumo de serviços médicos e demais artes de curar e assistir.

O hospital é visto, em principio, na perspectiva de instrumento de trabalho médico, seguindo o pensamento de Gonçalves:

"Entre eles (instrumentos de trabalho médico) aparece o local de trabalho como o mais importante, e, entre os locais onde se desenvolveu o trabalho médico na história, um deles assume, por referência ao próprio processo de trabalho, uma posição tão fundamental que sua importância dificilmente pode ser exagerada: o hospital" (Gonçalves, 1984: 69).

O exercício da prática de tratar e cuidar carece da apropriação do objeto de trabalho, para a qual é necessário um conjunto de instrumentos e Gonçalves identifica o primeiro grupo desses instrumentos como uma "dimensão intelectual do trabalho", enquanto o segundo grupo "corresponde à dimensão manual, transformadora" (Gonçalves, op. cit. p. 68/69). Um terceiro grupo de instrumentos deve ser considerado: aquele composto "pelas condições objetivas requeridas em geral para que o processo (de trabalho) aconteça" que "não se incorporam diretamente ao processo", porém, que se caracterizam porque sem elas este näo poderá efetuar-se ou só pode realizarse de maneira imperfeita" (K. Marx, El capital, I/1 219, apud, Gonçalves, 1984: $69)$.

Do cuidado e assistência individual, em nivel doméstico, praticado por familiares, sacerdotes, curandeiros, parteiras, enfermeiras ou médicos, das primeiras formas de aliviar as dores, tratar os doentes e tentar curá-los, chegouse à invenção do hospital. Lugar especial - estabelecimento - que reúne pessoas doentes para serem tratadas, onde os meios terapêuticos disponiveis para tratar os doentes são concentrados e onde a medicina se instala como instituição hegemônica. O uso dos termos assistência e cuidado é intencional. Os doentes foram cuidados, assistidos, tratados, por eles mesmos, por suas familias, por agentes encarregados dessas práticas e, posteriormente, em instituições onde as enfermeiras começaram a sua história, de acordo com as formas que cada sociedade estabeleceu para essa assistência.

Cuidar dos doentes define-se como prática, trabalho ou serviço e seus agentes - médicos, feiticeiros, sacerdotes, parteiras e posteriormente - movimentam-se nos templos, casas e nos estabelecimentos criados para esse fim. A doença, que a ciência tomou por objeto de conhecimento e de intervenção, é esquadrinhada, medida, classificada, explicada, enquanto fato, dor, risco, ameaça, presença da morte possível. Mas resta a questão do que fazer com 
os doentes, questão antiga e complexa que contém implicações coletivas e sociais "que complicam as tentativas de solucionar impedindo-lhes respostas simples e diretas" (Antunes, 1991: 11).

Medidas coletivas de prevenção de doenças e normas religiosas, cívicas e sanitárias já haviam sido adotadas na antigüidade; mas só a partir do século XIX tiveram sua definição formalmente baseada em conhecimentos médicos.

Mas é o hospital, cuja origem pode ser remontada aos templos gregos e aos hospitais militares romanos, enquanto estabelecimento de tratamento, que se destaca como o centro para onde convergem os sistemas contemporâneos de prestação de serviços de saúde. Localizar a origem dos hospitais nos lugares de acolhimentos dos doentes nos templos gregos, os Asclepiae, requer um esforço de reducionismo, uma vez, que "só tangencialmente e com diversas ressalvas, esses lugares poderiam ser relacionados aos hospitais modernos" (Antunes, 1991, p. 10-14).

Embora tenham sido construidos locais para o acolhimento de doentes em Roma, no século II, junto aos templos, configurando os primeiros estabelecimentos com caracteristicas hospitalares de que se tem noticia, as referências mais concretas dizem respeito a instituições dedicadas ao abrigo e tratamento de doentes, algo como hospitais militares, de campanha, mas que não se destinavam à população civil. Esses estabelecimentos antigos, que não tinham as características dos hospitais criados na Idade Média, destinavam-se a assistir e tratar os doentes, os quais, de acordo com os pressupostos da medicina grega, seriam os agentes de sua própria cura. Os templos de Esculápio, em um dos quais, o de Cós, Hipócrates teria se instruído, foram fechados em 335, por um Edito de Constantino, para serem substituidos pelos hospitais cristãos.

A partir do século IV, são fundados pelo clero, em nome dos fundamentos da fé, estabelecimentos de assistência e abrigo, que virão a tornar-se os hospitais cristãos.O Concilio de Nicéia, no ano de 325 , instruiu os bispos a criarem um Hospital em suas dioceses, reafirmando o cuidar dos enfermos como uma das sete tarefas da caridade cristã.

No século VI, Justiniano, (527-565) regulamentou os asilos existentes na época, entre eles os "nosocomia", que mais se aproximavam dos hospitais de hoje, e os "lobotrophia", que recebiam doentes sem esperança de cura, inválidos e leprosos, cujo sofrimento procuravam reduzir, além de proteger os sãos de seu contato repulsivo. Com a expansäo do cristianismo, os hospitais cristãos difundiram-se por toda a Europa, do oriente para o ocidente. Se a qualidade sanitária dos serviços prestados näo garantia a cura da maioria dos doentes, "os estudiosos convergem em reconhecer que a difusão dos hospitais da Idade Média ampliou consideravelmente a população beneficiada" (Antunes, 1991:40 e 41).

A transição da Antigüidade para a Idade Média não afetou singularmente a evolução dos hospitais. Estes continuaram difundindo-se dentro dos princípios cristãos, na medida em que o próprio cristianismo se expandia. O seu caráter 
institucional foi sendo modelado, implantando uma nova representação de saúde e doença que, contrapondo-se à idéia de uma origem natural das doenças, as explicavam como um castigo divino, um instrumento de provação. Embora, Segundo Antunes, (1991), muitas questões como a inserçăo dos conhecimentos empiricos na atuação dos estabelecimentos, o uso de aplicaçōes farmacêuticas e técnicas cirúrgicas, os procedimentos de atenção à doença $e$ a forma de organização e o potencial de reabilitação eram respondidas.

Até o século IX, os doentes foram tratados nos conventos, em espaços a eles destinados, mas, no ano de 816, o Concílio de Aix-la-Chapelle tornou obrigatória a construção de hospitais nos conventos. A fundação de ordens religiosas, voltadas para a assistência social e para o cuidado dos doentes, que se estabeleceram nesses hospitais, fizeram deles estabelecimentos mais religiosos que terapêuticos. A cristandade introduz a hospitalidade na atenção aos doentes, aos quais oferece o conforto da religião, o cuidado dos corpos e, se possivel, a recuperação de sua saúde. "[...] Através da fatalidade e da culpa a doença é inteiramente pensada na sua relação com o divino e com a natureza . Estas noções e outras semelhantes bastam para indicar ao doente seu lugar ao mesmo tempo que dão sentido à totalidade do universo" (Herzlich. C. e Pierret, 1984).

Do século XII em diante, as mudanças que vão determinar $\circ$ enfraquecimento do feudalismo e a retomada do crescimento das cidades $e$ as epidemias que varrem a Europa determinam, também, o aumento da demanda dos hospitais, nos quais atuavam tanto religiosos como leigos, e que, embora ainda não se constituissem no "locus" privilegiado de atuação do médico, era onde se praticava um cuidar próximo do que viria a ser enfermagem.

Com a crise da Igreja, cujo poder enfraquece juntamente com o regime feudal, os estabelecimentos hospitalares- religiosos mantidos por ela entram em decadência. Ao término da Idade Média, inúmeras congregações cristãs haviam fechado as casas que mantinham, transferindo para a iniciativa laica os serviços que vinham prestando, inclusive o de cuidados aos doentes. $E_{\text {, sob }}$ a direção das municipalidades, delineia-se o hospital geral. "Criados como instituição filantrópica, a um só tempo de auxilio material e espiritual, subtraídos da hierarquia eclesiástica pelas municipalidades ainda antes do Renascimento" (Antunes, 1991: 74 e 129).

Os hospitais preservaram, durante a Idade Média, suas características de estabelecimentos de assistência social, voltados " a outras obrigações tidas como de interesse coletivo: albergue dos pobres e doentes desprovidos e contenção de grupos populacionais considerados perigosos à vida das cidadesmendigos, imigrantes, portadores de moléstias repulsivas ou contagiosas" (Antunes, 1991: 75-76). Tais caracteristicas não se alteraram com a laicização: os hospitais mantiveram-se como uma combinação de hospedaria e asilo, instituição de abrigo e de tratamento de doentes, sem adquirir uma definição pragmática. E , seja por caridade cristã ou por força das epidemias que assolaram a Europa por toda a Idade Média, esses estabelecimentos se 
expandiram. O aumento da demanda dos serviços prestados pelos hospitais, que ocorreu com o crescimento do comércio e do fluxo migratório em direção às cidades, contribuiu para que esses estabelecimentos ampliassem as suas instalaçőes.

Na Inglaterra, segundo Thompsom \& Goldin, "o principal intuito que motivou a retomada dos hospitais, não teria sido outro senão a instituição de um sistema de ajuda social, minimamente eficaz, que permitisse fazer da cidade um lugar mais saudável para viver" (Thompsom Goldin, 1975, apud. Antunes, op. cit. p. 134).

A idéia que perpassa é que, enquanto no periodo medieval a igreja repassa aos pobres, em nome da caridade cristã, o que tira dela em forma de esmolas, com advento do Estado Moderno, a autoridade pública recolhe impostos para, em nome do interesse coletivo, assistir os necessitados. Herzlich e Pierret, (1984: 212) introduzem na análise do problema a noção do valor do capital biológico, valor para a sociedade, mas do qual o indivíduo é responsável. A doença socializada delimita o aparecimento e o reconhecimento de um personagem, o doente, face ao qual a sociedade tem deveres e obrigações.

A assistência pública, posta em funcionamento pelas autoridades politicas, teria a finalidade de remediar a insegurança que representariam, para o conjunto social, certas categorias de excluidos, assim como, a proteção desse valor que recém fora atribuído ao indivíduo. A repressão à vagabundagem, na Inglaterra, ainda no século XIV, ou a criação do Grande Bureau dos Pobres na França, em 1544, são exemplos das medidas de assistência pública referidas pelas autoridades, mais repressivas que assistenciais, representativas da presença do poder politico. "O aparecimento da assistência pública tem estado ligado à emergência e à consolidação do poder político representativo da sociedade" (G. Perin apud Herzlich e Pierret op. cit. p. 212). Nesse sentido explica-se que ela (a assistência pública) "tenha se revestido, em sua origem, de um significado mais politico que social, por se encontrar ligada a defesa e a consolidação das coletividades políticas em vias de formação" (Herzlich e Pierret, 1984: 213). Com efeito, os grupos particulares, tais como comunidades religiosas, as confrarias e associaçōes de operários assumiram o encargo de beneficência e de socorro, enquanto o poder público se afirmava progressivamente na manutenção da ordem e consagração dos valores comuns da sociedade global (Guerin, apud, Herzlich e Pierret, p. 213).

Mas o Estado Moderno formula, além de uma nova ciência, um novo conceito da relação do Estado com o cidadão, categoria recém estatuida. Montesquieu,(1689-1755) considera o Estado obrigado a assistir os desempregados e necessitados, afirmando: "No pais do comércio, onde muitas pessoas não têm um ofício, o Estado é, muitas vezes, obrigado a prover as necessidades dos anciãos, dos doentes, e dos órfãos." [...] "Qualquer esmola que se faz a um homem nas ruas não substitui a obrigação do Estado que deve a todos os cidadãos uma subsistência assegurada, a alimentação, a vestimenta conveniente, e um gênero de vida que não seja contrário à saúde." Montesquieu 
afirma, igualmente, a responsabilidade da sociedade civil com respeito à saúde dos cidadãos: "Que é mais importante que a saúde dos cidadãos? A força das gerações futuras, do Estado, não depende dos cuidados municipais?" (Montesquieu. 1966, p. 712, apud, Herzlich e Pierret, p. 213).

$\mathrm{Na}$ Declaração dos Direitos do Homem, de 24 de junho de 1793, está afirmado o dever da sociedade em relaçăo aos cidadãos desgraçados, desafortunados, através da ligação subsistência - trabalho- socorro. "Os socorros públicos são uma divida sagrada. A sociedade deve a subsistência dos cidadãos desafortunados, seja em sua procura de trabalho, seja assegurando os meios de existir àqueles que estão fora das condições de trabalhar" ( G. Perin, 1967, apud Herzlich e Pierret ${ }^{6}, 1984$ p. 212). Verifica-se assim que 0 reconhecimento da obrigação do Estado de cuidar da saúde dos cidadãos é postulado, portanto, há pelo menos dois séculos.

Herzlich e Pierret, (1984) entendem o direito da assistência, que aparece no ideário do século XVIII, e citam Hatzfeld, que afirma que: " uma teoria estatal de socorro e de beneficência parece complementária do individualismo mais radical em matéria de relações sociais"... "A incerteza da existência, expressão que empresta a Marx, constitui a origem das medidas sociais tomadas na sociedade na segunda metade do século XIX,[...]incerteza relativa a certas eventualidades da existência: a doença , a incapacidade, a velhice, encontravam o trabalhador desprevenido" (H. Hatzfeld. apud, Herzlich e Pierret, 1984: 214).

A doença, assimilada à incapacidade de trabalho, reconhecida pela medicina - os médicos participam da socializaçăo da doença, a identificam e nominam, é transformada e se inscreve nos novos laços da ordem social. Ser doente torna-se um direito: o direito de parar de trabalhar e de receber cuidados. $\mathrm{E} o$ doente aparece como um novo personagem na cena social. As transformações da patologia contribuem para a emergência de uma figura individualizada do doente. Novos deveres e direitos e um modo original de se relacionar com o conjunto social vão se definir.E a esse doente se reconhece, também, o direito ao tratamento de sua doença.

O nascimento da clínica que se acompanha da utilização de novas técnicas de diagnóstico e da conversão da arte de curar em oficio conduzem a medicina para o interior dos hospitais, lugar onde a observação dos doentes, que será pouco a pouco assumida pelas enfermeiras, poderá ser exercida em sua plenitude. Com o nascimento da clinica, a doença, os saberes que a explicavam e que permitiam tratá-la e os portadores desse saber convergem para o hospital.

O hospital define-se, então ,como o lugar onde os doentes podem ser observados, a causa de suas doenças descoberta, tratados e curados. E esse novo hospital, que näo mais se constitui em um lugar de abrigo e de asilo ou modelo disciplinar, destina-se a um outro tipo de doentes.

"Da profana incumbência de seqüestrar pobres, moribundos, doentes e vadios do meio social, escondendo o incômodo e disciplinando os corpos $\theta$ guardando-os até a morte, à nobre função de salvar vidas, o hospital tem 
percorrido um caminho complexo e tortuoso em busca do tecnicismo científico adequado às suas novas funções" (Pitta,. 1991: 41).

O surgimento do hospital como cenário privilegiado da tecnologia de tratamento e cura é fato relativamente recente e tem como marco da transformação de suas atribuições o final do século XVIII. Embora os hospitais daquela época não tivessem a função precípua de cura, é certo que alguns deles já a tinham (Pitta, 1991).

O (re)organização do hospital modifica o campo de prática médica, adequando-o ao desenvolvimento da clinica, novo instrumento de trabalho. $\mathrm{Na}$ construção de uma nova estrutura do saber médico, o campo da prática modifica-se: "Para que a clínica fosse possivel como forma de conhecimento foi necessária toda uma organização do campo hospitalar, uma nova definição do estatuto de enfermo na sociedade e a instauração de uma certa relação entre a assistência e a experiência, o auxilio e o saber. "[...]"A emergência da clínica como meio de trabalho coincide, portanto, com uma nova articulação entre a medicina e a sociedade" (Donnangelo ,1976: 18 e 19); Interpretação que também é encontrada em Foucault, que entende a constituição do espaço hospitalar como resultado de um movimento de toda a sociedade, movimento para o qual convergiram o atores e práticas sociais articuladas à prática médica, entre elas a enfermagem (Foucault, 1977).

Os primeiros personagens, em que se reconhecia a condição de doentes, que foram abrigados/segregados entre os muros do hospital-estabelecimento, ainda na Idade Média, foram os leprosos. Hospital-asilo, mais asilo-prisão que hospital, nele se instalou o modelo de exclusão, adotado, para leprosos e, posteriormente, para os loucos. Embora a lepra, assim como a loucura, não tenham se conformado por inteiro no conceito de doença que a medicina construíra.

A concepção do hospital como lugar disciplinador é identificada por Foucault que, contestando a tese de que o hospital tivesse qualquer função terapêutica na sua origem, entende ter existido sempre duas séries paralelas no cuidado das pessoas: "uma série médica , cujos cuidados eram exercidos em espaço não hospitalar, nas casas; e uma série hospitalar, onde a acolhida e disciplina da pobreza e das anomalias humanas eram administradas". Somente no século XVIII, inicia-se a era do hospital como dispositivo de cuidado assistencial.

"O personagem ideal do hospital até o século XVIII não é o doente que é preciso curar, mas o pobre que está morrendo, é alguém a quem se deve dar os últimos cuidados e o último sacramento. Esta é a função essencial do hospital [...] e o pessoal hospitalar não era fundamentalmente designado a realizar a cura do doente, mas conseguir sua própria salvação. Era um pessoal caritativo religioso ou leigo- que estava no hospital para fazer uma obra de caridade que Ihe assegurasse salvação eterna" (Foucault, 1981: 101-102).

Hospitais e lazaretos, hospicios, penitenciárias, estabelecimentos de educação e abrigo, convertem-se em instâncias de controle individual 
funcional. A atividade de controle público exercida por aqueles estabelecimentos assumiu uma forma inaudita de enfrentamento das doenças transmissíveis: a segregação social dos doentes e sua retenção em instituições (Antunes, 1991: 79). Renova-se a função do hospital: de estabelecimento de abrigo e cuidado torna-se, então, estabelecimento disciplinador.

Os novos projetos, apresentados ao final do século XVIII, assinalam o "nascimento do hospital terapêtico, instrumento destinado a curar". Segundo Foucault, os dois passos da transformação que deu origem ao hospital contemporâneo, a saber, a imposição de mecanismos disciplinares para reger as atividades dos hospitais e a conversão da disciplina resultante em disciplina biomédica, seriam, ainda hoje, seus principais traços descritivos. E não menos importante foi a sua ocupação pela medicina, que, incorporando os conhecimentos da ciência moderna e da clínica, se torna a instituição principal de assistência.

A emergência da questão da cidadania, com a construção do Estado Moderno, significou um aumento da demanda por serviços de saúde, inclusive de hospitais. A idéia de que o doente precisa de cuidados e abrigo é anterior ao critério de possibilidade de lhes despender tratamento e cuidado. A organização de serviços hospitaleiros, mais que hospitalares, surgida no Império Romano, inspirava-se seguramente em razões de ordem econômica; durante a Idade Média, a motivação explícita foi a caridade cristã; Mas, "ao promoverem a exclusão e o isolamento asilar de ponderáveis segmentos sociais, os hospitais prestaram-se ao controle e ao disciplinamento da vida urbana" (Antunes, 1991: 161). Quando, a partir do século XVIII, a medicina veio a sẹr incorporada ao hospital, assumindo o seu controle, passou-se a acreditar que esse pudesse exercer uma ação terapêutica eficaz. Segundo Antunes, é então que o hospital adquire o estatuto da contemporaneidade (Antunes, 1991: 162-163).

Com a expansão do capitalismo, uma nova transformação vai ocorrer nos hospitais. A apropriação dos meios de produção de serviços de saúde pela prática médica, renovada pela invenção da clínica como meio de conhecimento e de trabalho, ocupação dos hospitais e a transformação das práticas e saberes ali concentrados vão se constituir em mecanismos que consolidam sua inserção no processo de produção capitalista.

A reorganização do campo hospitalar transforma a prática médica mas mantém as instituições asilares e suas características excludentes, mesmo porque os saberes que constituiam a clínica não davam conta, ainda, das doenças ali abrigadas ou segregadas.

A demanda crescente por serviços de saúde, seja devido ao aumento do volume da população, seja devido às mudanças nas concepções de saúde e de suas necessidades ou à extensão do significado da necessidade de assistência, transforma os serviços de saúde. O domínio médico se amplia: do doente ao são, do individuo aos coletivos de indivíduos. E essa ampliação significa, necessariamente, a busca de novas estratégias de atuação. 
O enorme desenvolvimento das ciências biológicas, no século XIX, que transforma os paradigmas que explicam a saúde e a doença, produz mudanças significativas nos hospitais com a introdução da antissepsia e a renovação da enfermagem que adquire foros de profissão, graças à inestimável contribuição de Florence Nightingale. Mas os hospitais ainda polarizam a assistência que se estende às comunidades.

$E$ os efeitos do capitalismo se fazem sentir: os custos crescentes dos serviços hospitalares, para onde foram levados os equipamentos que a nova tecnologia médica exige, fazem do hospital um estabelecimento onde cada unidade monetária investida precisa ser transformada em serviço, isto é, em produto.

"Os meios de produção (na produção médica) não se sucedem meramente. Correspondem a e fundamentam modalidades de articulação entre o trabalho médico, seu objeto, seus produtos e a forma de seu consumo ..." (Donnangelo, 1976: 18).

Convergem dois fatos para a determinação de um novo modo de lidar com a segregação. O primeiro destes fatos refere-se ao que ocorre nos hospitais, onde o capital se concentra, sob a forma de novos equipamentos, os quais devem gerar serviços, produtos e valores, onde não cabem doentes crônicos, incuráveis, que não significam um retorno dó capital investido. Cada leito hospitalar, com o auxílio das novas tecnologias, constitui um meio de produção e os crônicos os imobiliza.

O hospital, onde o trabalho realiza um capital, contribuindo para sua reprodução, precisa ser um espaço dinâmico, produtivo. Não é um asilo. "Não é um lugar para guardar doente".

O segundo fato observado diz respeito ao que vem ocorrendo no domínio da ciência e da técnica. A ciência aprendeu que as doenças infecciosas têm uma causa, um agente, e mais, aprendeu o modo de tratar ou evitar a maioria das doenças causadas por um agente infeccioso. Melhor ainda, aprendeu que essa terapêutica, essa prevenção, não precisa do hospital como meio de trabalho exclusivo.

Estavam dadas as condições para que o modelo de atenção à saúde superasse a representação do hospital como lugar de doentes: o lugar destes é a sociedade, a familia, a comunidade. O hospital é recurso de uso especializado e temporário. Era só um tempo. Tempo necessário para que os trabalhadores de saúde aprendessem essa nova versão do processo de tratar, dominassem as novas técnicas; tempo necessário para que as pessoas, o público, se acostumassem com a nova representação das doenças e dos doentes e a internalizassem em suas representações.

Do mesmo modo que o hospital recolhimento e abrigo da Idade Média e o hospital lugar de exclusão de categorias indesejáveis do século XVIII, o hospital, espaço onde a clínica se organiza e se instala, assume, com a apreensão da prática médica pelo modo de produção capitalista, uma nova função: função 
utilitária, pragmática de lugar de produção de serviços, de realização de lucros e mais valia. Porque os serviços médicos tornaram-se produtos e adquiriram um valor de mercado. Enquanto produtos que dependem de fatores de produção, integram a mão de obra e a tecnologia. A função social do hospital vai sendo delegada a outras instâncias da sociedade. As familias e comunidades passam a ser cobradas de uma maior participação no cuidado das pessoas, atribuindo a elas tarefas antes cometidas aos profissionais especializados localizados no interior do espaço hospitalar. Descaracterizam-se, em muitas situaçōes, algumas competências profissionais, no esforço de esvaziar o espaço hospitalar de pacientes que, não dependendo cuidados sofisticados, não são rentáveis economicamente para o novo hospital. Porque nesse novo hospital não cabem os crônicos, os deficientes, os necessitados de cuidados especificos de enfermagem: eles não dão lucro .

\section{BIBLIOGRAFIA}

1. ANTUNES, José Leopoldo Ferreira. Hospital-Instituição e História Social. São Paulo: Editora Letras \& Letras, 1991.

2. DONNANGELO, Maria Cecilia F. \& PEREIRA, L. Saúde e Sociedade. Säo Paulo: Duas Cidades, 1976. 124p.

3. FOUCAULT, M. Microfísica do Poder. Rio de Janeiro: Graal, 1981.

4. O Nascimento da Clínica. Rio de Janeiro: Forense Editora. 1977.

5. GONÇALVES, Ricardo Bruno Mendes. Medicina y Historia; raices sociales de trabajo medico. México: Siglo Veintiuno Editores, S. A. , 1984. p. 204.

6. HERZLICH, C. \& PIERRET, J. Malades d'hier, malades d'aujourd'hui. Paris: Payot, 1984.

7. PITTA, Ana. O Hospital-dor e morte como ofício. São Paulo: Editora Hucitec, 1991. 